\title{
The most important news at ASCO 2009
}

l: am often asked my opinion of the most important presentation at the annual ASCO meetings. I gave up long ago trying to explain that it is impossible to read the thousands of abstracts and rate them accordingly, but like everyone else I do keep my eyes peeled to note something of special interest. In most years the pickings are actually fairly slim; breakthrough results rarely make it to ASCO. However, this year it was easy. Buried amongst all the other news tidbits ema-

\section{That is why the} announcement by Merck and AstraZeneca is so important. It establishes a new paradigm 77 the dilemma that after investing millions of dollars on developing an agent that blocks a theoretically important pathway they either have to ditch it, on the basis of the usual standards of efficacy for drug approval, or wait another decade of testing in combination with other promising agents. Furthermore, patients with cancer have to wait with them. In fact, this is what has happened. Most of the new and useful targeted treatments would never have been marketed if they had not been tested in combination with another agent, usually a cytotoxic drug.

Third, most biopharmaceutical companies do not have the resources to develop multiple targeted therapies at the same time. They do believe, however, that it is in the best interests of their shareholders to focus on getting their drug approved, by itself, above all else. This usually does not involve testing it jointly with a drug from another company before it is approved.

So, we are at a time when we have identified many important biological pathways cancer cells use to divide and survive, and easily have the capacity to develop inhibitors of these pathways, but our old inflexible approach does not allow us to use our imagination and test these agents early on in ways that the best scientific minds think might achieve synergy. That is why the announcement by Merck and AstraZeneca is so important. It establishes a new paradigm. We need to push competitive interests back even further. I would suggest that the next step is to do the same thing as each drug actually reaches the clinic-combination phase I trials, if you will. The problems this approach will create for pharmaceutical companies trying to sort out relative value for their shareholders, and for regulatory agencies worried about safety, should not be underestimated, but they too can be solved. It is truly the way of the future for cancer treatment.

doi:10.1038/nrclinonc.2009.93
Vincent T. DeVita Jr is the Editor-in-Chief of Nature Reviews Clinical Oncology.

Competing interests The author declares no competing interests. 